\title{
Interaction of thermal and kinetic parameters for a liquid-liquid reaction system: Application to vegetable oils epoxidation by peroxycarboxylic acid
}

\author{
Sébastien Leveneur ${ }^{\mathrm{a}, \mathrm{b}, 1, *}$, Junliu Zheng ${ }^{\mathrm{a}, \mathrm{c}}$, Bechara Taouk ${ }^{\mathrm{a}}$, Fabrice Burel ${ }^{\mathrm{c}}$, Johan Wärnå ${ }^{\mathrm{b}, \mathrm{d}}$, \\ Tapio Salmi ${ }^{\text {b }}$ \\ a LSPC - Laboratoire de Sécurité des Procédés Chimiques, INSA Rouen, 685 Avenue de l'Université, FR-76801 Saint-Etienne-du-Rouvray, France \\ ${ }^{\mathrm{b}}$ Laboratory of Industrial Chemistry and Reaction Engineering, Process Chemistry Centre, Åbo Akademi University, Biskopsgatan 8, FI-20500 Åbo/Turku, \\ Finland \\ ${ }^{\mathrm{C}}$ Normandie Université, INSA de Rouen, CNRS UMR 6270 PBS E' FR 3038, Avenue de l'Université, 76801 Saint-Etienne-du-Rouvray, France \\ ${ }^{\mathrm{d}}$ Umeå University, Chemical-Biological Center, Technical Chemistry, SE-901 87 Umeå, Sweden
}

\section{A R T I C L E I N F O}

\section{Article history:}

Received 24 October 2013

Received in revised form 14 January 2014

Accepted 19 January 2014

Available online 16 February 2014

\section{Keywords:}

Kinetic modeling

Calorimetry

Liquid-liquid reaction system

Epoxidation of vegetable oils

\begin{abstract}
A B S T R A C T
A mathematical model was developed to analyze an exothermic liquid-liquid reaction system using epoxidation of oleic acid by peroxyformic acid formed in situ as an example. Kinetic and thermal parameters were included, mass transfer parameters were eliminated from the model and evaporation/ condensation was taken into account. A calorimetric semi-batch reactor under isoperibolic mode was used in the experimental work. Different initial aqueous-phase concentrations of $\mathrm{H}_{2} \mathrm{O}_{2}$ [6.5-8.8 mol/l], water [44-45 mol/l], molar flow rate of formic acid [0.02-0.54 mol $/ \mathrm{min}]$, initial reaction temperature [50-70 ${ }^{\circ} \mathrm{C}$ ] and amount of organic phase [34-46 wt.\%] were studied. A non-linear regression method was used to estimate kinetic (e.g., rate constant at average temperature and activation energy) and thermal parameters (e.g., reaction enthalpy) of the epoxidation and ring-opening reactions. The standard reaction enthalpy changes were estimated to be $-116 \mathrm{~kJ} / \mathrm{mol}$ for epoxidation reaction and $-50 \mathrm{~kJ} / \mathrm{mol}$ for the ring opening.
\end{abstract}

(C) 2014 Taiwan Institute of Chemical Engineers. Published by Elsevier B.V. All rights reserved.

\section{Introduction}

The world consumption of lubricants is estimated to be 40 million tons per year, used in very different areas from car engines to office chairs. As in fuel industry, the majority of lubricants are petroleum-derived. Even though depletion of crude oil will increase the price of petroleum raw material, the reason to use bio-lubricants instead of petro-based one is mainly environmental. Indeed, several studies have shown that $30-40 \%$ of lubricants escape into the environment through such routes as spills, leaks and evaporation [1]. For these reasons, research has been focused on an inexpensive, non-toxic and renewable source of lubricants, i.e., bio-based lubricants. At present, the cost of bio-based lubricant

\footnotetext{
Abbreviations: EOA, epoxidized oleic acid; FA, formic acid; OA, oleic acid; PFA, peroxyformic acid.

* Corresponding author at: LSPC - Laboratoire de Sécurité des Procédés Chimiques, INSA Rouen, 685 Avenue de l'Université, FR-76801 Saint-Etienne-duRouvray, France. Tel.: +33 2329566 54; fax: +33 232956652 .

E-mail address: sebastien.leveneur@insa-rouen.fr (S. Leveneur).

${ }^{1}$ Tel.: +33 2329566 54; fax: +33232956652.
}

is higher than petro-based lubricants, but compared to maintenance and energy costs, it is a minor factor (Fig. 1) [2].

The production of bio-lubricant is based on the use of vegetable or animal oils, and several ways of synthesis exist: esterification or transesterification as biodiesel, selective hydrogenation, or epoxidation of the oils by peroxycarboxylic acids. The latter route of production follows the philosophy of Green Chemistry, because there is no production of waste such as glycerol or the use of explosive reactants such as hydrogen. Epoxidized vegetable oils can also be used for different purposes, such as intermediates for polymer synthesis, as plasticizers or as scavenger during the synthesis of PVC. Compared to petroleum-derived products, they present several advantages: low toxicity and biodegradability.

There are several ways of synthesis of epoxidized vegetable oils [3-6], but the use of peroxycarboxylic acids, e.g., peroxyformic or peroxyacetic acids, is the most efficient and greener way [3]. It is a liquid-liquid reaction system, where the peroxycarboxylic acid is formed in situ from the carboxylic acid and hydrogen peroxide.

The literature review concerning the kinetics of vegetable oil epoxydation is quite vast. However, one should differentiate between the studies carried out under isothermal and 


\begin{tabular}{|c|c|}
\hline \multicolumn{2}{|c|}{ Nomenclature } \\
\hline$A$ & heat transfer area $\left[\mathrm{m}^{2}\right]$ \\
\hline$C_{p}$ & constant-pressure heat capacity $[\mathrm{J} / \mathrm{K}]$ \\
\hline $\bar{C}_{P}$ & constant-pressure heat capacity per $\mathrm{mol}[\mathrm{J} / \mathrm{mol} / \mathrm{K}]$ \\
\hline$\hat{C}_{P}$ & constant-pressure heat capacity per mass $[\mathrm{J} / \mathrm{kg} / \mathrm{K}]$ \\
\hline$E_{\mathrm{a}}$ & activation energy $[\mathrm{J} / \mathrm{mol}]$ \\
\hline$H$ & enthalpy $[\mathrm{J}]$ \\
\hline $\bar{H}$ & molar enthalpy $[\mathrm{J} / \mathrm{mol}]$ \\
\hline$\Delta H_{\mathrm{r}}^{o}$ & standard reaction enthalpy $[\mathrm{kJ} / \mathrm{mol}]$ \\
\hline$\Delta H_{v}$ & heat of vaporization $[\mathrm{J} / \mathrm{mol}]$ \\
\hline$K^{\mathrm{c}}$ & equilibrium constant, based on concentrations \\
\hline$K^{\mathrm{T}}$ & $\begin{array}{l}\text { thermodynamic equilibrium constant, based on } \\
\text { activities }\end{array}$ \\
\hline$K_{\text {WATER }}$ & equilibrium molar ratio of water \\
\hline$K_{\mathrm{FA}}$ & equilibrium molar ratio of formic acid \\
\hline$K_{\mathrm{PFA}}$ & equilibrium molar ratio of peroxyformic acid \\
\hline$k$ & rate constant $\left[1^{2} / \mathrm{mol} / \mathrm{s}\right]$ \\
\hline$k_{\text {decomp }}$ & decomposition rate constant $[\mathrm{s}]$ \\
\hline$m$ & mass $[\mathrm{kg}]$ \\
\hline$\dot{n}$ & flow of the amount of substance $[\mathrm{mol} / \mathrm{s}]$ \\
\hline$P$ & pressure \\
\hline$Q_{\mathrm{f}}$ & volumetric flow rate $[1 / \mathrm{s}]$ \\
\hline$\dot{Q}_{c}$ & electrical calibration [W] \\
\hline$\dot{Q}$ & heat transfer rate $[\mathrm{W}]$ \\
\hline$\dot{Q}_{\mathrm{ex}}$ & heat flux exchanged with the reactor jacket [W] \\
\hline$\dot{Q}_{\text {loss }}$ & heat flux lost through the top of the reactor [W] \\
\hline$R$ & gas constant $[\mathrm{J} / \mathrm{K} / \mathrm{mol}]$ \\
\hline$R^{2}$ & coefficient of explanation [\%] \\
\hline$r_{i}$ & reaction rate $[\mathrm{mol} / \mathrm{l} / \mathrm{s}]$ \\
\hline$T$ & temperature \\
\hline$U$ & overall heat transfer coefficient $[\mathrm{W} / \mathrm{m} / \mathrm{K}]$ \\
\hline$Q_{\mathrm{HCOOH}}$ & volumetric flow rate of formic acid [1/s] \\
\hline$V_{\mathrm{R}}$ & reaction volume [1] \\
\hline$X$ & conversion \\
\hline \multicolumn{2}{|c|}{ Greek letters } \\
\hline$\beta$ & proportionality factor [J/s/atm] \\
\hline$v_{i j}$ & stoichiometric coefficient \\
\hline$\rho$ & mass density [kg/l] \\
\hline$\omega$ & objective function \\
\hline$\tau$ & residence time \\
\hline \multicolumn{2}{|c|}{ Subscripts and superscripts } \\
\hline add & addition \\
\hline ave & average \\
\hline $\mathrm{aq}$ & aqueous phase \\
\hline decomp & decomposition \\
\hline eq & equilibrium state \\
\hline $\mathrm{f}$ & feed flow \\
\hline FAD & formic acid dissociation \\
\hline het & heterogeneous \\
\hline hom & homogeneous \\
\hline in & input \\
\hline$j$ & component $j$ \\
\hline org & organic phase \\
\hline out & output \\
\hline perh & perhydrolysis \\
\hline ref & reference state \\
\hline
\end{tabular}

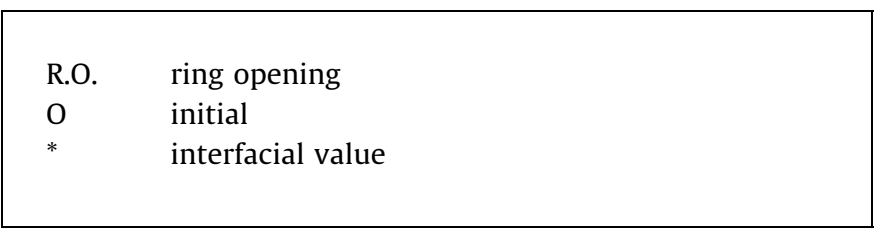

non-isothermal conditions. To the best of our knowledge, only the group of Santacesaria et al. $[7,8]$ has proposed a complete model coupling the energy and mass balances for this system.

A kinetic model was developed by coupling mass and energy balances, but avoiding the use of mass transfer parameters and taking into account the evaporation/condensation of aqueous phase. A calorimetric reactor was designed and operated in semibatch under isoperibolic mode. A model molecule representing vegetable oils was used: oleic acid. Indeed, the structure of this free fatty acid is present in several vegetable oils.

\section{Experimental}

\subsection{Apparatus and experimental procedures}

The experiments were carried out in the experimental apparatus described in a previous article of our group, Leveneur et al. [9]. The reactor set-up is shown in Fig. 2.

In a first step, water, hydrogen peroxide and oleic acid were added together into the reactor. As the desired temperature was reached, a first calibration step, i.e., by the Joule effect, was carried out to measure the heat capacity of the reaction mixture and the overall heat transfer coefficient through the jacket. Then, a preheated solution of formic acid was added through a dosing pump. A last calibration was made at the end of the reaction.

To prevent any contamination, which initiate the catalytic decomposition of peroxide species, all parts of the reactor system being in contact with the reaction solution were washed with hydrochloric acid, followed by another washing, with a phosphatefree detergent solution.

Table 1 introduces the experimental matrix

Different reaction enthalpies are involved in the system. To take into account all the thermal effects, even the lowest one, a microcalorimeter was used. An isothermal micro-calorimeter, namely C80 SETARAM, was used. This calorimeter uses the Calvet design detector in which a sample and reference cells are totally surrounded by an array of thermocouple detectors allowing for

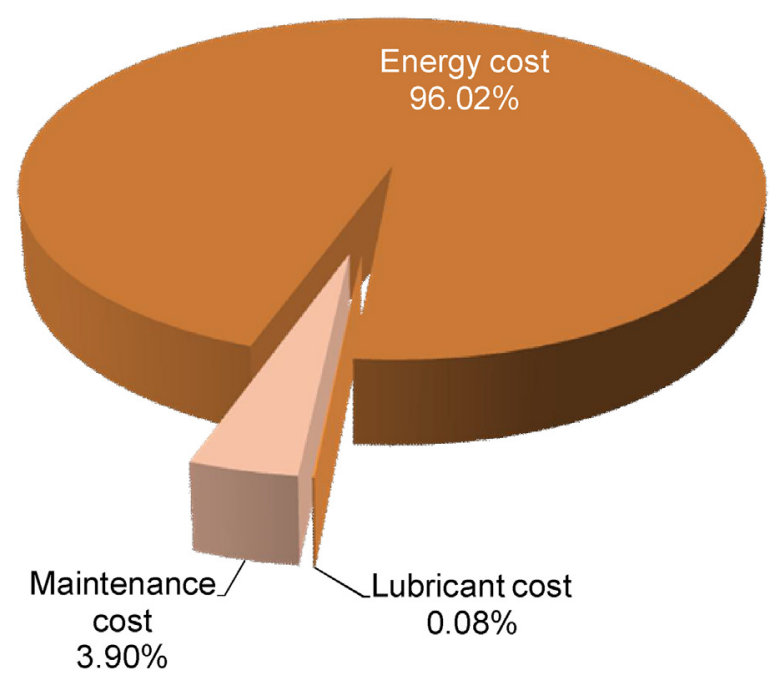

Fig. 1. Relative lubricant, energy and maintenance costs. 


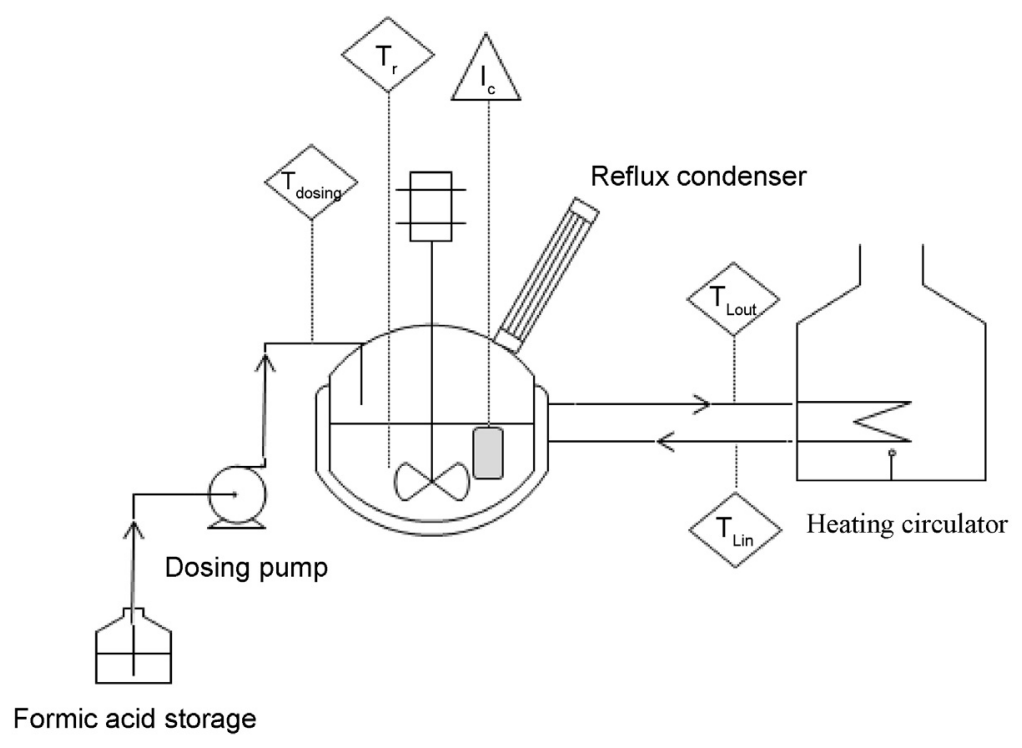

Fig. 2. Schematic representation of the experimental setup.

the measurement of all heat evolved. Membrane Mixing Cells made in Hastelloy were used (Fig. 3). Two different compartments were separated by a PTFE membrane. This measurement was performed to measure the enthalpy of the ring opening reaction, thus the upper compartment was filled with water and formic acid and the lower one with epoxidized oleic acid. In the reference cell, the upper part was filled with water and the lower one with epoxidized oleic acid. When the desired temperature was reached and the heat flow was stable, the membrane was drilled by the stirrer and agitation was started.

\subsection{Analytical methods}

Samples were withdrawn from the reaction mixture by a plastic syringe (to avoid contamination of the solution by trace of metals), then separation of the organic phase from the aqueous phase was done by centrifugation. The concentration of hydrogen peroxide was determined by titration using a standard solution of ammonium cerium sulphate $(0.1 \mathrm{~N})$ [10]. The concentration of oxirane was determined by the method of Jay using a $0.1 \mathrm{M}$ perchloric acid in acetic acid [11].

\section{Results and discussion}

\subsection{Mechanism}

Fig. 4 shows a simplified mechanism of the different reactions occurring during the epoxydation of oleic acid by peroxycarboxylic acids $[7,8,12-21]$. In a first step, peroxyformic acid is formed in situ by formic acid perhydrolysis. Then, peroxyformic acid transfers to the organic phase to epoxidize the oleic acid double bond. Ring opening occurs between epoxidized oleic acid and water from the

Table 1

Experimental matrix.

\begin{tabular}{ll}
\hline Reaction temperature & $50-70{ }^{\circ} \mathrm{C}$ \\
Rotation speed & $370-650 \mathrm{rpm}$ \\
Initial organic compound [wt.\%] & $34-46 \%$ \\
$\dot{n}_{\mathrm{FA}}$ & $0.02-0.54 \mathrm{~mol} / \mathrm{min}$ \\
{$\left[\mathrm{H}_{2} \mathrm{O}_{2}\right]_{0, \mathrm{aq}}$} & $6.5-8.8 \mathrm{~mol} / \mathrm{l}$ \\
{$\left[\mathrm{H}_{2} \mathrm{O}\right]_{0, \mathrm{aq}}$} & $44-48 \mathrm{~mol} / \mathrm{l}$ \\
{$[\mathrm{Oleic} \text { acid }]_{0, \mathrm{org}}$} & $3.15 \mathrm{~mol} / \mathrm{l}$ \\
Time of addition & $2-40 \mathrm{~min}$ \\
\hline
\end{tabular}

aqueous phase at the interface [7]. According to several authors $[7,8,12-21]$, the solubility of hydrogen peroxide in the organic phase is negligible.

Campanella et al. [12-21] have studied different mechanisms of ring opening. It appears that this reaction is complex, because different nucleophilic agents can be involved, i.e., water, hydrogen peroxide, formic or peroxyformic acids. For the sake of simplicity, only the ring opening reaction due to the hydroxonium ions was considered [7]. As illustrated by Fig. 5, the activation of oxirane by protons is the first step of the ring opening reaction.

\subsection{Kinetic equations}

The peroxyformic acid synthesis was described by a previous article of our group [9]. Two main reactions occur in the aqueous phase, formic acid perhydrolysis and peroxyformic acid decomposition, respectively. The rate equations are shown below:

$r_{\text {perh }}=k_{\text {perh }} \cdot\left(\left[\mathrm{HCO}_{2} \mathrm{H}\right]_{\mathrm{aq}} \cdot\left[\mathrm{H}_{2} \mathrm{O}_{2}\right]_{\mathrm{aq}}-\frac{1}{K^{\mathrm{C}}}\left[\mathrm{HCO}_{3} \mathrm{H}\right]_{\mathrm{aq}} \cdot\left[\mathrm{H}_{2} \mathrm{O}\right]_{\mathrm{aq}}\right)$

$r_{\text {decomp }}=k_{\text {decomp } \cdot}\left[\mathrm{HCO}_{3} \mathrm{H}\right]_{\mathrm{aq}}$

where $K^{\mathrm{C}}$ is the equilibrium constant of the perhydrolysis reaction, which has been determined in a previous article of our group [9].

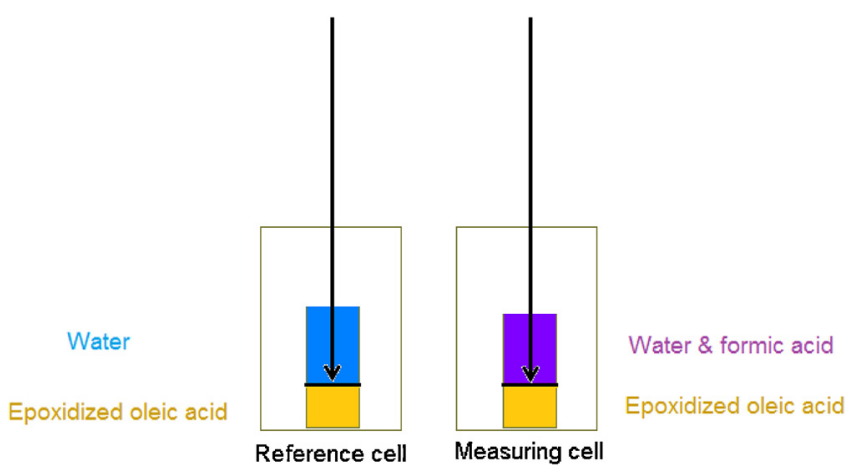

Fig. 3. Schematic view of the C80 cells. 




Aqueous phase

Fig. 4. Simplified mechanism for fatty acid epoxidation.

In the organic phase, epoxidation and ring opening proceed simultaneously. The rate equations for the organic phase are summarized below:

-Epoxidation:

$r_{\mathrm{Ep}}=k_{\mathrm{Ep}} \cdot\left[\mathrm{HCO}_{3} \mathrm{H}\right]_{\mathrm{org}} \cdot[\text { oleic acid }]_{\mathrm{org}}$

-Ring opening:

$r_{\text {R.o. }}=k_{\text {R.O. } .}[\text { Epoxide }]_{\text {org }} \cdot\left[\mathrm{H}_{3} \mathrm{O}^{+}\right]_{\text {org }}$

By taking into account rapid phase equilibria, the rate expressions for the epoxidation and ring opening can be rearranged to:

$$
\begin{aligned}
r_{\mathrm{Ep}} & =k_{\mathrm{Ep}} \cdot[\mathrm{PFA}]_{\mathrm{org}} \cdot[\mathrm{OA}]_{\mathrm{org}}=k_{\mathrm{Ep}} \cdot[\mathrm{OA}]_{\mathrm{org}} \cdot \frac{[\mathrm{PFA}]_{\mathrm{aq}}}{K_{\mathrm{PFA}}} \\
& =k_{\mathrm{Ep}}^{\prime} \cdot[\mathrm{OA}]_{\mathrm{org}} \cdot[\mathrm{PFA}]_{\mathrm{aq}}
\end{aligned}
$$

$$
\begin{aligned}
r_{\text {R.o. }} & =k_{\text {R.o. } .}[\text { Epoxide }]_{\text {org }} \cdot \frac{\left[\mathrm{H}_{3} \mathrm{O}^{+}\right]_{\mathrm{aq}}}{K_{\mathrm{H}_{3} \mathrm{O}^{+}}} \\
& =k_{\text {R.o. }}^{\prime} \cdot[\text { Epoxide }]_{\mathrm{org}} \cdot\left[\mathrm{H}_{3} \mathrm{O}^{+}\right]_{\mathrm{aq}}
\end{aligned}
$$

where $K_{\mathrm{PFA}}=[\mathrm{PFA}]_{\mathrm{aq}} /[\mathrm{PFA}]_{\text {org }}$ is the distribution coefficient of peroxyformic acid between the aqueous and organic phase, and $K_{\mathrm{H}_{3} \mathrm{O}^{+}}=\left[\mathrm{H}_{3} \mathrm{O}^{+}\right]_{\mathrm{aq}} /\left[\mathrm{H}_{3} \mathrm{O}^{+}\right]_{\mathrm{org}}$ is the distribution coefficient of hydroxonium ions.

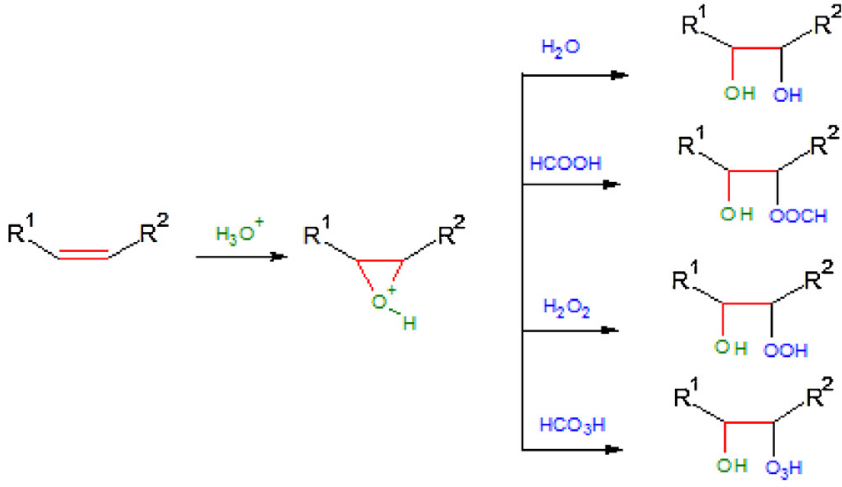

Fig. 5. Ring opening reactions.

\subsection{Modeling of semi-batch reactor}

\subsubsection{Influence of agitation speed}

Preliminary experiments indicated that a minimum agitation speed of $370 \mathrm{rpm}$ was necessary to ensure complete backmixing of both phases. To reveal the effects of the agitation speed, similar experiments were carried out at different speeds ranging from 370 to $650 \mathrm{rpm}$. Fig. 6 depicts the effect of the agitation speed on the hydrogen peroxide conversion.

It can be noticed that the effect of agitation speed is negligible for speeds exceeding $500 \mathrm{rpm}$, and thus one can neglect any mass transfer limitation due to rotating speed. Thus, kinetic experiments were performed at $650 \mathrm{rpm}$.

\subsubsection{Energy balance}

The temperatures of the aqueous and organic phases were equal because of vigorous stirring. Thus, the system can be described with a single energy balance:

$$
\begin{aligned}
m_{\mathrm{R}} \cdot \hat{C}_{\mathrm{PR}} \cdot \frac{d T_{\mathrm{R}}}{d t}= & -\left(r_{\mathrm{perh}} \cdot \Delta H_{\mathrm{Rperh}}+r_{\mathrm{decomp}} \cdot \Delta H_{\mathrm{Rdecomp}}\right) \cdot V_{\mathrm{aq}} \\
& -\left(r_{\mathrm{Ep}} \cdot \Delta H_{\mathrm{REp}}+r_{\mathrm{R} . \mathrm{O} \cdot} \cdot \Delta H_{\mathrm{RR} \cdot \mathrm{O} .}\right) \cdot V_{\mathrm{org}}+U \cdot A \cdot\left(T_{j}\right. \\
& \left.-T_{\mathrm{R}}\right)-q_{\mathrm{loss} \text { due to evaporation }} \\
& +[\mathrm{HCOOH}]_{\text {feed }} \cdot Q_{\mathrm{HCOOH}} \cdot \bar{C}_{P, \mathrm{HCOOH}} \cdot\left(T_{j}-T_{\mathrm{R}}\right)
\end{aligned}
$$

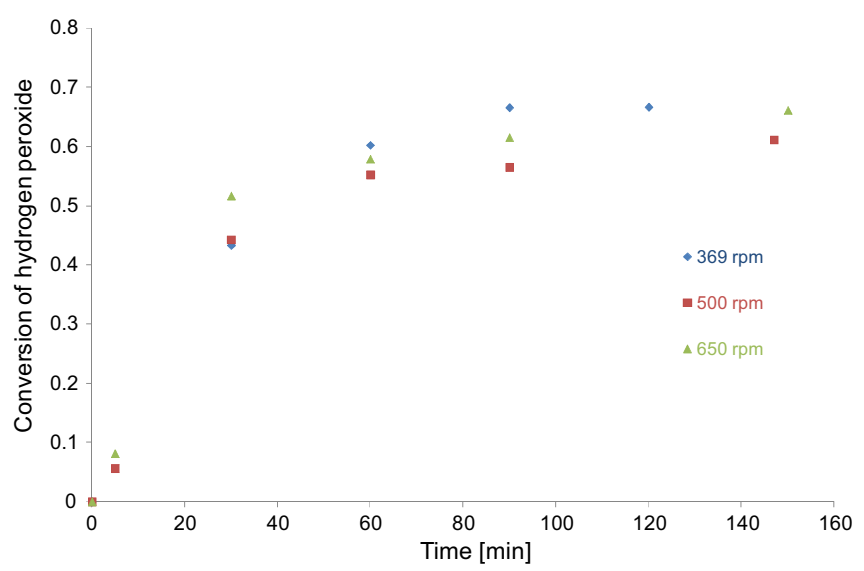

Fig. 6. Effect of rotating speed on hydrogen peroxide conversion at an initial temperature of $60{ }^{\circ} \mathrm{C}$, formic acid feeding rate of $2.50 \mathrm{~g} / \mathrm{min}$ and a $30 \mathrm{wt} . \%$ of organic phase. 


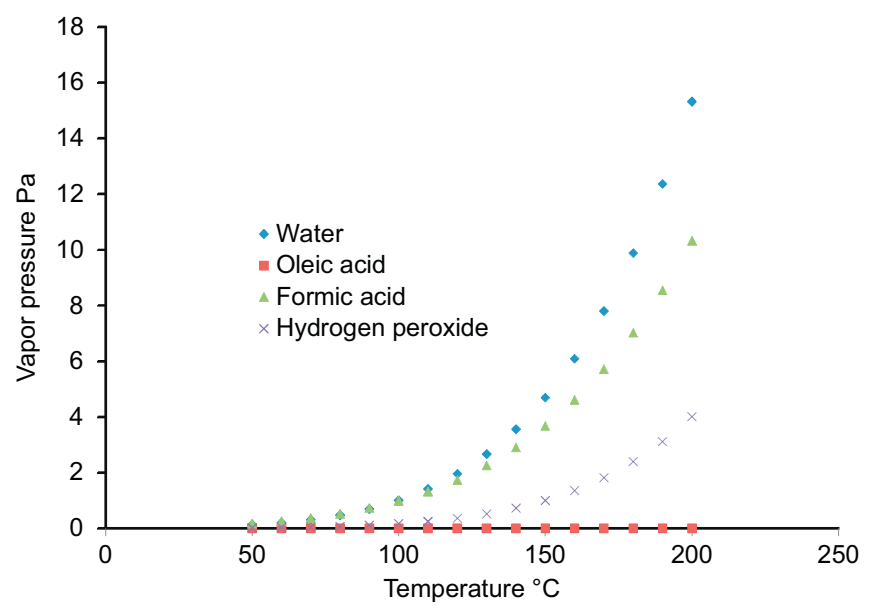

Fig. 7. Vapor pressure of compounds.

where $\hat{C}_{P}$ is constant-pressure specific mass-based heat capacity, $m_{\mathrm{R}}$ is the mass of the reaction system, $\rho_{\mathrm{R}}$ is the mass density of the reaction system, $[\mathrm{HCOOH}]_{\text {feed }}$ is the concentration of formic acid in the feed stream, $Q_{\mathrm{HcoOH}}$ is volumetric flow rate of formic acid and $\bar{C}_{P, \mathrm{HCOOH}}$ is the formic acid constant-pressure heat capacity per mol equal to $95.4 \mathrm{~J} / \mathrm{mol} / \mathrm{K}$.

According to Ulbrich et al. [22], the heat loss through the top of the reactor is mainly due to the evaporation of the reaction mixture. Some of the vapor produced may condense at the cold cover and cold droplets flow back to the reactor. This can be considered to be the major contribution to heat losses. The heat losses can be assumed to be proportional to the total vapor pressure of the system:

$q_{\text {loss due to evaporation }}=\beta \cdot \sum x_{j} P_{j}$

where $\beta$ is a constant, $x_{j}$ and $P_{j}$ are the molar fraction and the vapor pressure of component $j$, respectively.

The vapor pressure can be estimated from the ClausiusClapeyron equation:

$P\left(T_{1}\right)=P\left(T_{2}\right) \exp \left(\frac{\Delta H_{v}}{R} \cdot\left(\frac{1}{T_{1}}-\frac{1}{T_{2}}\right)\right)$

where $\Delta H_{v}$ is the heat of vaporization, $R$ the general gas constant, $P\left(T_{1}\right)$ and $P\left(T_{2}\right)$, the vapor pressure at temperature $T_{1}$ and $T_{2}$, respectively. Because water and formic acid are the most volatile compounds, thus only their evaporation was considered (Fig. 7).

From a previous work of our group [9], the coefficient $\beta$ was found to be equal to $3.36 \mathrm{~J} / \mathrm{s} / \mathrm{atm}$. The evaporation is mainly due to the aqueous part, thus $\beta$ was kept at $3.36 \mathrm{~J} / \mathrm{s} / \mathrm{atm}$ in the model.

\subsubsection{Mass balance for aqueous and organic phases}

In the aqueous phase, mass balance of compound $(i)$ is written as:

$\dot{n}_{i, \mathrm{aq}, \mathrm{in}}+\sum v_{i j} V_{\mathrm{aq}} \cdot r_{\mathrm{aq}, j}=\frac{d n_{i, \mathrm{aq}}}{d t}+N_{i} \cdot A$

By introducing the following simplified notations: $\dot{V}_{\mathrm{aq}}=d V_{\mathrm{aq}} / d t, \quad a=(A) / V_{\mathrm{T}}, \quad \alpha^{-1}=\tau / \tau_{\mathrm{aq}}, \quad \tau=V_{\mathrm{T}} / Q_{\mathrm{aq}} \quad$ and $\tau_{\mathrm{aq}}=V_{\mathrm{aq}} / Q_{\mathrm{aq}}$, mass balance for the aqueous phase becomes:

$$
\left.\begin{array}{l}
C_{\mathrm{feed}, i} \cdot \dot{V}_{\mathrm{aq}}+\sum v_{i j} \cdot V_{\mathrm{aq}} \cdot r_{\mathrm{aq}, j}=V_{\mathrm{aq}} \cdot \frac{d C_{i, \mathrm{aq}}}{d t}+N_{i} \cdot a \cdot V_{\mathrm{T}}+C_{i, \mathrm{aq}} \cdot \dot{V}_{\mathrm{aq}} \\
\Leftrightarrow C_{\mathrm{feed}, i}+\sum v_{i j} \cdot \tau_{\mathrm{aq}} \cdot r_{\mathrm{aq}, j}=\tau_{\mathrm{aq}} \cdot \frac{d C_{i, \mathrm{aq}}}{d t}+N_{i} \cdot a \cdot \tau+C_{i, \mathrm{aq}} \\
\Leftrightarrow \frac{d C_{i, \mathrm{aq}}}{d t}=\sum v_{i j} \cdot r_{\mathrm{aq}, j}-\frac{N_{i} \cdot a}{\alpha}+\frac{\left(C_{\mathrm{feed}, i}-C_{i, \mathrm{aq}}\right)}{\tau_{\mathrm{aq}}}
\end{array}\right\}
$$

By introducing $\beta^{-1}=V_{\mathrm{T}} / V_{\text {org }}$, mass balance for the organic phase becomes:

$\left.\begin{array}{l}\frac{d C_{i, \mathrm{org}}}{d t} \cdot V_{\text {org }}=N_{i} \cdot a \cdot V_{\mathrm{T}}+V_{\text {org }} \cdot \sum v_{i j} \cdot r_{\text {org }, j} \\ \Leftrightarrow \frac{d C_{i, \text { org }}}{d t}=N_{i} \cdot \frac{a \cdot V_{\mathrm{T}}}{V_{\text {org }}}+\sum v_{i j} \cdot r_{\text {org }, j} \\ =\frac{N_{i} \cdot a}{\beta}+\sum v_{i j} \cdot r_{\text {org }, j}=\frac{N_{i} \cdot a}{1-\alpha}+\sum v_{i j} \cdot r_{\text {org }, j}\end{array}\right\}$

One should notice that $\alpha+\beta=1$.

Eq. (12) can be rewritten to:

$\alpha \cdot \frac{d C_{i, \mathrm{aq}}}{d t}=\alpha \cdot \sum v_{i j} \cdot r_{\mathrm{aq}, j}-N_{i} \cdot a+\alpha \cdot \frac{\left(C_{\mathrm{feed}, i}-C_{i, \mathrm{aq}}\right)}{\tau_{\mathrm{aq}}}$

and Eq. (13) can be written as:

$(1-\alpha) \cdot \frac{d C_{i, \text { org }}}{d t}=N_{i} \cdot a+(1-\alpha) \cdot \sum v_{i j} \cdot r_{\mathrm{org}, j}$

Addition of Eqs. (14) and (15) leads to:

$$
\begin{aligned}
\alpha \cdot \frac{d C_{i, \mathrm{aq}}}{d t}+(1-\alpha) \cdot \frac{d C_{i, \mathrm{org}}}{d t} & =\alpha \cdot \sum v_{i j} \cdot r_{\mathrm{aq}, j}+(1-\alpha) \cdot \sum v_{i j} \cdot r_{\mathrm{org}, j} \\
& +\alpha \cdot \frac{\left(C_{\mathrm{feed}, i}-C_{i, \mathrm{aq}}\right)}{\tau_{\mathrm{aq}}}
\end{aligned}
$$

By using the same methodology as described in an article of our group [23], mass transfer coefficient of peroxyformic acid in aqueous was estimated by using Calderbank and Moo-Young correlation and diffusion coefficient of peroxyformic acid in organic phase was estimated by using the correlation of Scheibel. The Hatta number was found to be lower than 1 so interfacial mass transfer can be assumed to be rapid. Thus, the concentrations in the aqueous and organic phases can be directly related by $K_{i}=$ $[i]_{\mathrm{aq}}^{*} /[i]_{\mathrm{org}}^{*} \approx\left([i]_{\mathrm{aq}} /[i]_{\mathrm{org}}\right)_{\text {at the equilibrium }}$ and Eq. (16) becomes:

$\frac{d C_{i, \text { org }}}{d t}=\left(\alpha \cdot K_{i}+1-\alpha\right)^{-1}$

$\cdot\left(\left(\alpha \cdot \sum v_{i j} \cdot r_{\mathrm{aq}, j}+(1-\alpha) \cdot \sum v_{i j} \cdot r_{\mathrm{org}, j}\right)+\alpha \cdot \frac{\left(C_{\mathrm{feed}, i}-K_{i} \cdot C_{i, \mathrm{org}}\right)}{\tau_{\mathrm{aq}}}\right)($

In the same way, mass balance in the aqueous phase can be written as:

$\frac{d C_{i, \mathrm{aq}}}{d t}=\left(\alpha+\frac{1-\alpha}{K_{i}}\right)^{-1}$
$\cdot\left(\left(\alpha \cdot \sum \nu_{i j} \cdot r_{\mathrm{aq}, j}+(1-\alpha) \cdot \sum \nu_{i j} \cdot r_{\mathrm{org}, j}\right)+\alpha \cdot \frac{\left(C_{\mathrm{feed}, i}-C_{i, \mathrm{aq}}\right)}{\tau_{\mathrm{aq}}}\right)$

The benefit of the treatment presented above is that the system can be described either using the aqueous or organic phase concentrations and the distribution coefficients, and the use of mass transfer parameters is avoided. The compounds in the aqueous phase are water, hydrogen peroxide, formic and peroxyformic acids. The compounds in the organic phase are oleic acid, epoxidized oleic acid and diol oleic acid.

For the sake of simplicity, one can suppose that $K_{\mathrm{FA}}, K_{\mathrm{PFA}}, K_{\mathrm{W}}$ and $K_{\mathrm{Hp}} \rightarrow \infty$ and $K_{\mathrm{OA}}, K_{\mathrm{Ep}}$ and $K_{\mathrm{Hy}} \rightarrow 0$. Thus, application of Eqs. (17) and (18) gives the mass balances for the different compounds as summarized below:

$$
\begin{aligned}
& \frac{d C_{\mathrm{FA}, \mathrm{aq}}}{d t}=\left(-r_{\mathrm{perh}}+\frac{1-\alpha}{\alpha} \cdot r_{\mathrm{Ep}}+\frac{\left(C_{\mathrm{feed}, i}-C_{\mathrm{FA}, \mathrm{aq}}\right)}{\tau_{\mathrm{aq}}}\right) \\
& \frac{d C_{\mathrm{W}, \mathrm{aq}}}{d t}=\left(r_{\mathrm{perh}}+r_{\text {decomp }}-\frac{1-\alpha}{\alpha} r_{\mathrm{R} .0 .}-\frac{C_{\mathrm{W}, \mathrm{aq}}}{\tau_{\mathrm{aq}}}\right)
\end{aligned}
$$


$\frac{d C_{\mathrm{HP}, \mathrm{aq}}}{d t}=\left(-r_{\mathrm{perh}}-\frac{C_{\mathrm{HP}, \mathrm{aq}}}{\tau_{\mathrm{aq}}}\right)$

$\frac{d C_{\mathrm{PFA}, \mathrm{aq}}}{d t}=\left(r_{\mathrm{perh}}-r_{\mathrm{decomp}}-\frac{(1-\alpha) \cdot r_{\mathrm{Ep}}}{\alpha}-\frac{C_{\mathrm{PFA}, \mathrm{aq}}}{\tau_{\mathrm{aq}}}\right)$

$\frac{d C_{\mathrm{OA}, \text { org }}}{d t}=-r_{\mathrm{Ep}}$

$\frac{d C_{\mathrm{Ep}, \mathrm{org}}}{d t}=r_{\mathrm{Ep}}-r_{\mathrm{R} . \mathrm{O}}$

$\frac{d C_{\mathrm{Hy}, \mathrm{org}}}{d t}=r_{\mathrm{R} . \mathrm{O}}$

\subsection{Experimental determination of $\mathrm{UA}$ and $\mathrm{C}_{\mathrm{p}}$}

The same procedure was used to determine the overall heat transfer coefficient $U A$ and the heat capacity $C_{p}$ [9]. By using the electrical calibration, i.e., the Joule heating, it was possible to determine experimentally the parameters $U A$ and $\hat{C}_{p j}$. Eq. (8) becomes:

$$
\begin{aligned}
V_{\mathrm{R}} \cdot \rho_{\mathrm{R}} \cdot \hat{C}_{P \mathrm{R}} \cdot \frac{d T_{\mathrm{R}}}{d t}= & -\sum_{i} r_{i} \cdot \Delta H_{\mathrm{R} i} \cdot V_{\mathrm{R}}+C_{j \mathrm{f}} \cdot Q_{\mathrm{f}} \cdot \bar{C}_{p j} \cdot\left(T_{\mathrm{f}}-T_{\mathrm{R}}\right) \\
& +\dot{Q}_{\text {loss }}+\dot{Q}_{\mathrm{ex}}+\dot{Q}_{\mathrm{c}}
\end{aligned}
$$

where $\dot{Q}_{c}$ is the electrical calibration performed before and at the end of the experiments. The calibration was performed in the absence of chemical reactions, in the absence of reactant feeding and in a temperature range, where evaporation can be neglected. Thus, the model becomes

$m_{\mathrm{R}} \cdot \hat{C}_{P \mathrm{R}} \cdot \frac{d T_{\mathrm{R}}}{d t}=U \cdot A \cdot\left(T_{j}-T_{\mathrm{R}}\right)+\dot{Q}_{\mathrm{C}}$

Fig. 8 illustrates temperature evolution from a calibration experiment. Based on the data, it is possible to determine $U A$ and $\hat{C}_{P R}$. Table 2 shows typical values of $\hat{C}_{P R}$ at different reaction temperatures.

The specific heat capacity was supposed to evolve linearly with the yield of epoxidized oleic acid $\left(Y_{\mathrm{EOA}}\right)$ :

$\hat{C}_{P \mathrm{R}}=\alpha \cdot Y_{\mathrm{EOA}}+\left(\hat{C}_{P \mathrm{R}}\right)_{0}$

where $\alpha$ is a coefficient determined from the experimental data.
Table 2

Thermal parameters of the reactor.

\begin{tabular}{llrrr}
\hline & Tinitial [K] & 323.15 & 333.15 & 343.15 \\
Before addition & $\hat{C}_{P R}[\mathrm{~J} / \mathrm{g} / \mathrm{K}]$ & 3.04 & 2.04 & 2.03 \\
End of reaction & $\hat{C}_{P R}[\mathrm{~J} / \mathrm{g} / \mathrm{K}]$ & 2.55 & 1.70 & 1.84 \\
\hline
\end{tabular}

The coefficient $U A$ depends on temperature, viscosity and heat surface exchange area (linked to the feed ratio and addition time). For the sake of simplicity, it was supposed to vary linearly with the conversion of hydrogen peroxide (which depends on the concentration of formic acid):

$U A=\delta \cdot X_{\mathrm{H}_{2} \mathrm{O}_{2}}+(U A)_{0}$

where $\delta$ is a coefficient determined from the experimental data. This parameter varies from 3 to $6.5 \mathrm{~W} / \mathrm{K}$.

\subsection{Ring-opening reaction study}

In the epoxidation reaction system, thermal effect due to ringopening reaction is lower than epoxidation one. Thus, some complementary experiments are needed.

\subsubsection{Kinetic study}

To diminish the number of estimated parameters, a separate kinetic study dedicated to ring-opening reaction was performed. Experiments were carried out in the same reactor set-up, but only epoxidized oleic acid was used in the organic phase.

Table 3 introduces the experimental matrix.

Experimental results showed that the ring-opening reaction was mainly due to the presence of formic acid. It was observed that the reactor temperature was constant, thus one can consider this reaction system under isothermal conditions.

Thus, one can neglect the energy balance and only the following ODEs should be considered:

$\frac{d C_{\mathrm{FA}, \mathrm{aq}}}{d t}=\left(\frac{\left(C_{\mathrm{feed}, i}-C_{\mathrm{FA}, \mathrm{aq}}\right)}{\tau_{\mathrm{aq}}}\right)$

$\frac{d C_{\mathrm{Ep}, \mathrm{org}}}{d t}=-r_{\mathrm{R} . \mathrm{O}}$

$\frac{d C_{\mathrm{Hy}, \mathrm{org}}}{d t}=r_{\mathrm{R} . \mathrm{O}}$

The ODEs 30-32 were solved numerically by a special software MODEST [24]. The objective function $\omega$ was minimized by using

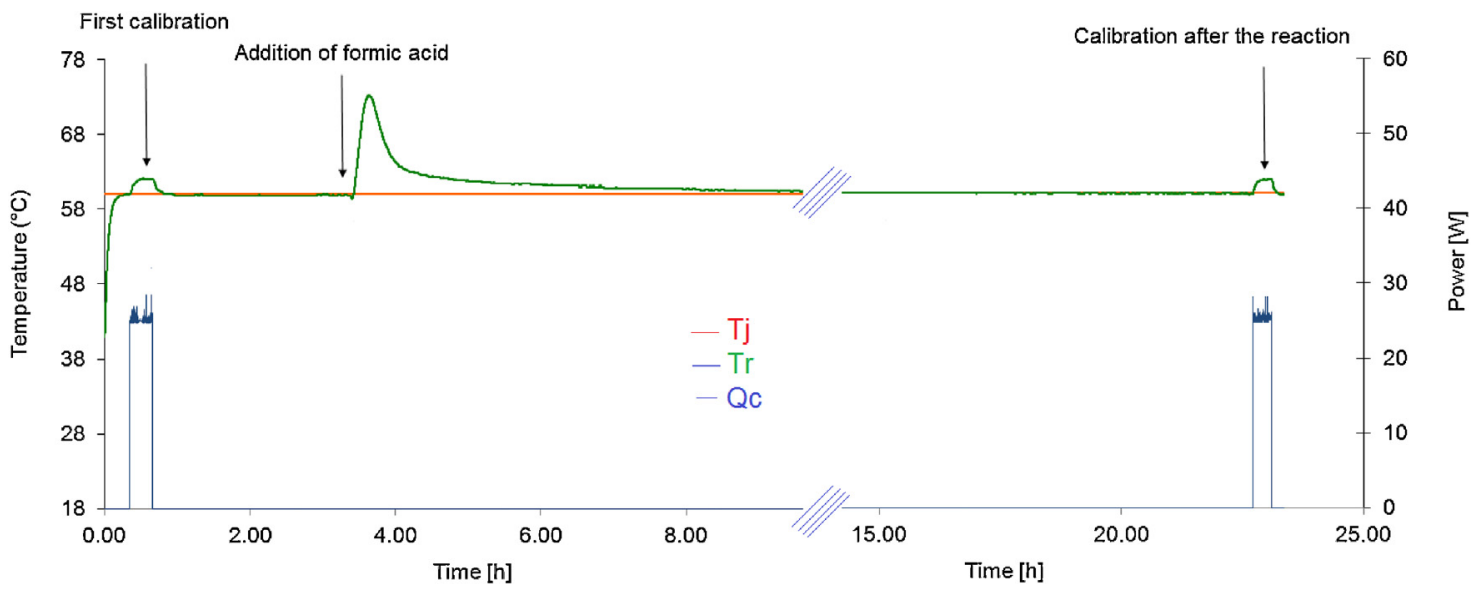

Fig. 8. Temperature evolution during an experiment. 

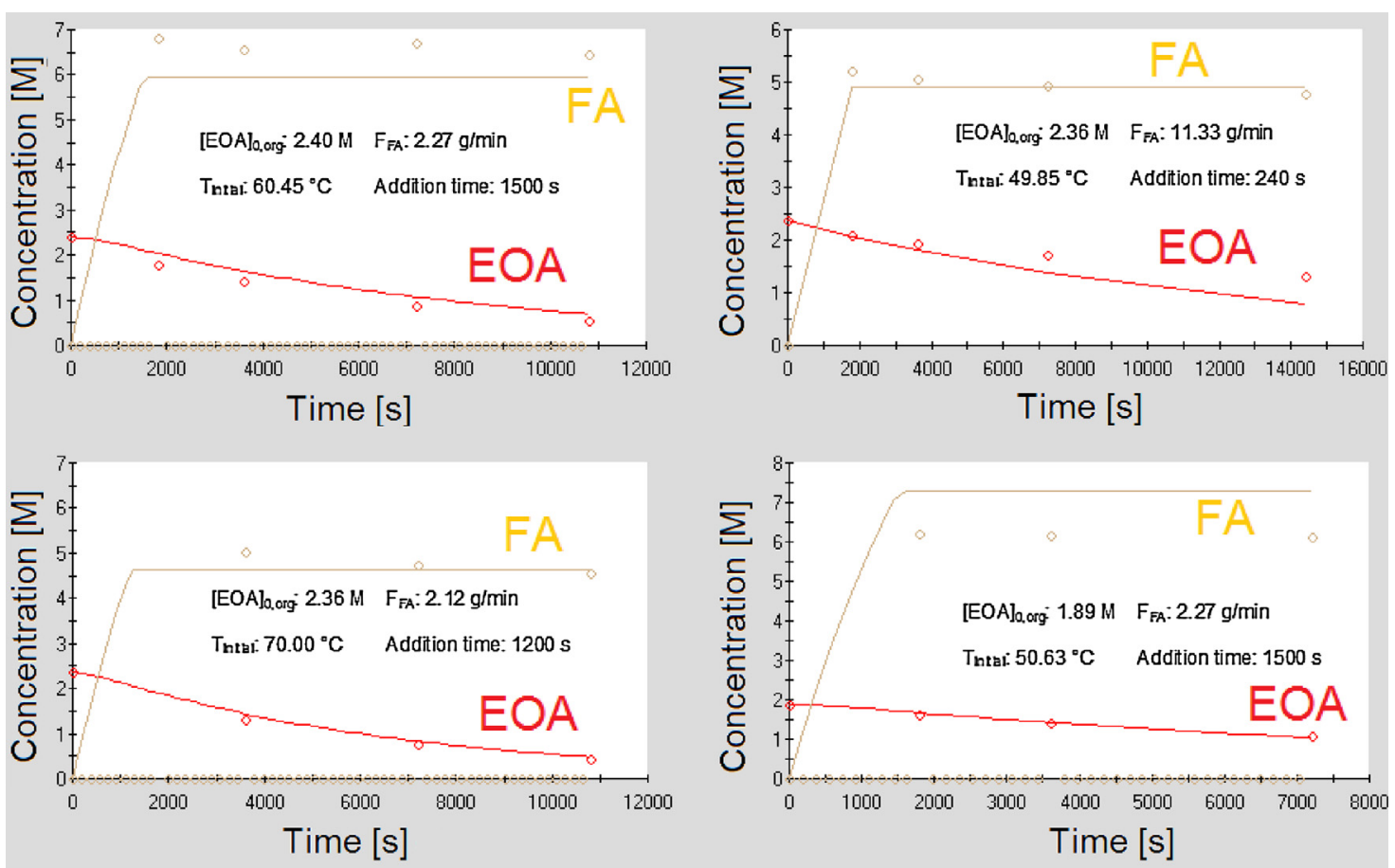

Fig. 9. Fit of the model to the experimental points.

Simplex and Levenberg-Marquardt algorithms. The objective function for the concentrations was defined as $\omega=\sum\left(C_{i}-C_{i}\right)$, where $C_{i}$ is the experimental concentration and $C$ is the estimated concentration obtained from the model. The concentrations of FA from the aqueous phase and concentration of epoxidized oleic acid EOA from the organic phase were included in the objective function with equal weights.

The temperature dependences of the rate constants were described by a modified Arrhenius equation:

$k=k_{\mathrm{ave}} \exp \left(\frac{-E_{a}}{R}\left(\frac{1}{T}-\frac{1}{T_{\mathrm{ave}}}\right)\right)$

where $k_{\text {ave }}=A e^{-\left(E_{a} / R T_{\text {ave }}\right)}, T_{\text {ave }}$ is the average temperature of the set of experiments. The goal of this modification was to minimize the correlation between the frequency factor and the activation energy during the parameter estimation.

The coefficient of determination of the model is defined as follows:

$R^{2}=1-\frac{\sum\left(C_{i}-\hat{C}_{i}\right)^{2}}{\sum\left(C_{i}-\bar{C}_{i}\right)^{2}}$

where $\bar{C}_{i}$ is the mean value of the observed concentration. The coefficient of determination of this model exceeded 95\%, showing a very good correspondence between the experimental and calculated values (Fig. 9). Table 4 gives the estimated and statistical data for the parameters.

Table 3

Experimental matrix for ring-opening reaction.

\begin{tabular}{ll}
\hline Reaction temperature & $50-70{ }^{\circ} \mathrm{C}$ \\
Rotation speed & $650 \mathrm{rpm}$ \\
Initial organic compound [wt.\%] & $40-46 \%$ \\
$\dot{n}_{\mathrm{FA}}$ & $0.02-0.24 \mathrm{~mol} / \mathrm{min}$ \\
{$\left[\mathrm{H}_{2} \mathrm{O}_{2}\right]_{0, \text { aq }}$} & 0 \\
{$\left[\mathrm{H}_{2} \mathrm{O}\right]_{0, \mathrm{aq}}$} & 5.55 \\
{$[\text { Epoxidized oleic acid }]_{0, \text { org }}$} & $1.9-2.4$ \\
Time of addition & $4-25 \mathrm{~min}$ \\
\hline
\end{tabular}

Due to the slow kinetics of this reaction, the temperature mode became isothermal in our experimental conditions. However, the enthalpy of ring-opening reaction is not negligible, and it was estimated in the following model.

\subsubsection{Thermal study}

As observed previously, a degradation study carried out under our experimental conditions has shown that the system was isothermal. This does not mean that the reaction is not exothermic neither than one can neglect its enthalpy of reaction. In order to check the magnitude of this parameter, C80 SETARAM calorimeter was used.

Fig. 10 represents the evolution of heat as a function of time in case of the ring opening of epoxidized oleic acid at $50{ }^{\circ} \mathrm{C}$.

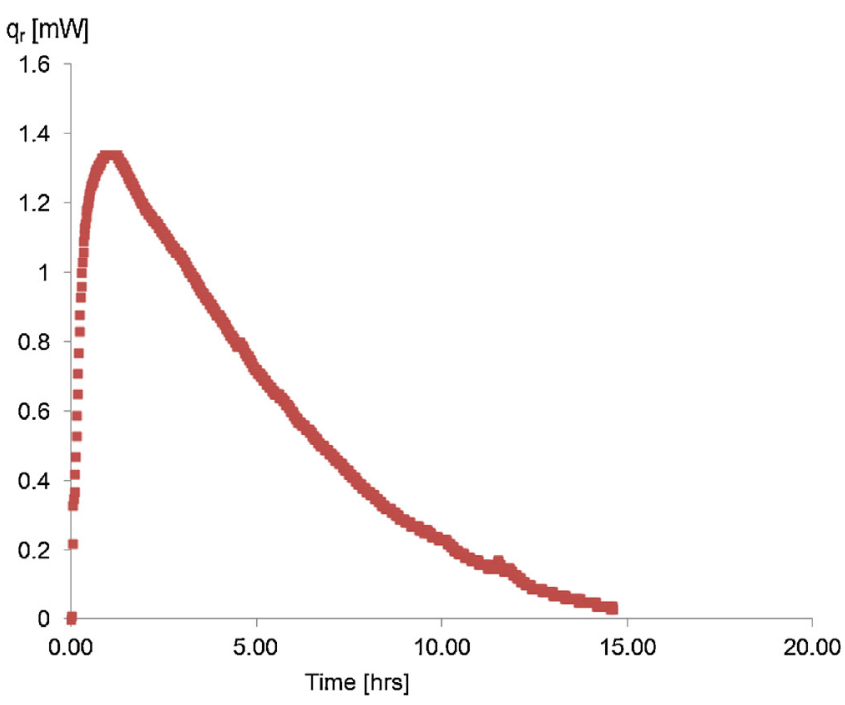

Fig. 10. Heat profiles for the ring opening of epoxidized oleic acid at $50{ }^{\circ} \mathrm{C}$. 
Table 4

Estimated and statistical data at $T_{\text {ave }}=340 \mathrm{~K}$ for the ring-opening reaction.

\begin{tabular}{lccc}
\hline & Estimated & Standard error & Standard error \% \\
\hline$k_{\text {R.O }}[1 / \mathrm{mol} / \mathrm{s}]$ & $0.90 \times 10^{-5}$ & $0.69 \times 10^{-6}$ & 7.6 \\
$E_{\text {a,R.O. }}[\mathrm{J} / \mathrm{mol}]$ & 34,000 & 6700 & 19.6 \\
\hline
\end{tabular}

By integrating the graph of Fig. 10, one can get the amount of heat released by the reaction, $Q_{r}(J)$. To get the enthalpy of reaction, one should divide $Q_{r}$ by the reaction extent, $\xi$. After $15 \mathrm{~h}$ of reaction, all the epoxidized oleic acid was converted. The enthalpy of ring opening for the epoxidized oleic acid was estimated to be $-50 \mathrm{~kJ} / \mathrm{mol}$. This value can be assumed to be constant over a range of temperature.

\subsection{Modeling and statistical results}

As described in the previous section, the ODEs 19-25 and 26 were solved numerically by a special software MODEST [24]. The objective function $\omega$ was minimized by using Simplex and Levenberg-Marquardt algorithms. The objective ${ }_{2}$ unction for the concentrations was defined as $\omega=w_{i} \sum\left(y_{i}-y_{i}\right)$, where $y$ is the experimental observable (concentration or temperature) and $\hat{y}$ is the estimated observable obtained from the model. Temperature signal was measured on-line whereas concentrations were analyzed off-line. Thus, number of data for temperature is higher than for concentrations. For that reason, a weight factor $w$ is introduced. Its value is equal to zero when no sample was analyzed otherwise its value is equal to 1 .
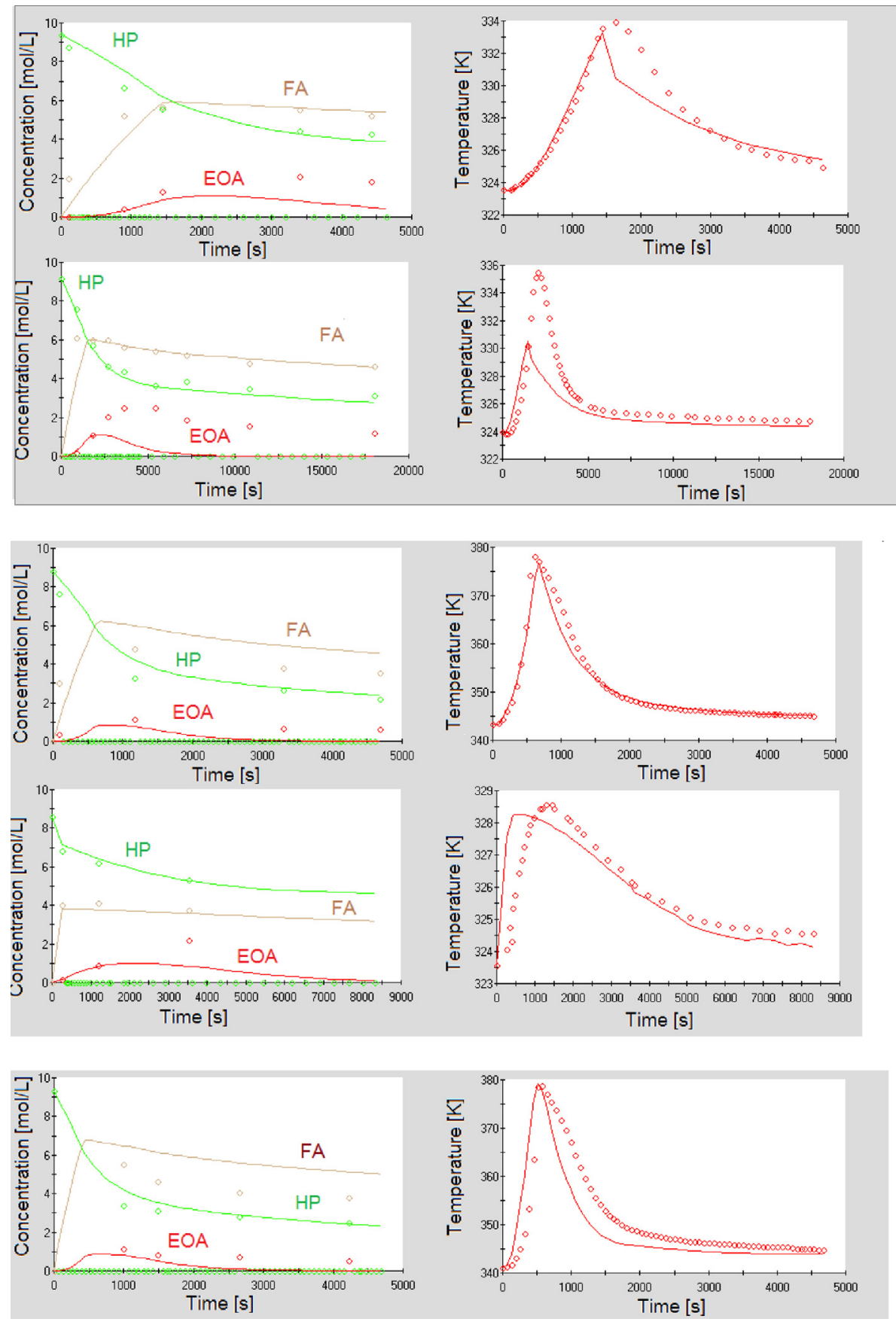

Fig. 11. Fit of the model to the experimental observations.
$\left[\mathrm{H}_{2} \mathrm{O}_{2}\right]_{0, \mathrm{sq}}=9.38 \mathrm{~mol} \cdot \mathrm{L}^{-1} \mathrm{~F}_{\mathrm{FA}}=2.45 \mathrm{~g} \cdot \mathrm{min}^{-1}$ $[O A]_{0,0 \mathrm{~g}}=3.16 \mathrm{~mol} \cdot \mathrm{L}^{-1} \quad$ Addition time $=1454 \mathrm{~s}$ $\mathrm{T}_{\text {init }}=50.4^{\circ} \mathrm{C}$

$\left[\mathrm{H}_{2} \mathrm{O}_{2}\right]_{0, \mathrm{aq}}=9.15 \mathrm{~mol} \cdot \mathrm{L}^{-1} \mathrm{~F}_{\mathrm{FA}}=227 \mathrm{~g} \cdot \mathrm{min}^{-1}$ $[\mathrm{OA}]_{0, \text { org }}=3.16 \mathrm{~mol} . \mathrm{L}^{-1} \quad$ Addition time $=1500 \mathrm{~s}$ $\mathrm{T}_{\text {init }}=50.8^{\circ} \mathrm{C}$

$\left.\mathrm{H}_{2} \mathrm{O}_{2}\right]_{0, \mathrm{gq}}=8.80 \mathrm{~mol} \cdot \mathrm{L}^{-1} \mathrm{~F}_{\mathrm{FA}}=6.29 \mathrm{~g} \cdot \mathrm{min}^{-1}$ $\mathrm{OA}]_{0,0 \mathrm{rg}}=3.16 \mathrm{~mol} . \mathrm{L}^{-1} \quad$ Addition time $=637 \mathrm{~s}$ $\mathrm{T}_{\text {init }}=70.1^{\circ} \mathrm{C}$

$\left[\mathrm{H}_{2} \mathrm{O}_{2}\right]_{0, \text { aq }}=8.58 \mathrm{~mol} \cdot \mathrm{L}^{-1} \mathrm{~F}_{\mathrm{FA}}=24.45 \mathrm{~g} \cdot \mathrm{min}^{-1}$ $[\mathrm{OA}]_{0, \text { org }}=3.16 \mathrm{~mol}^{-\mathrm{L}^{-1}}$ Addition time $=120 \mathrm{~s}$ $\mathrm{T}_{\text {int }}=50.4^{\circ} \mathrm{C}$

$\left[\mathrm{H}_{2} \mathrm{O}_{2}\right]_{0,8 q}=9.33 \mathrm{~mol} \cdot \mathrm{L}^{-1} \mathrm{~F}_{\mathrm{FA}}=9.96 \mathrm{~g} \cdot \mathrm{min}^{-1}$ $[\mathrm{OA}]_{0, \text { org }}=3.16 \mathrm{~mol} \mathrm{~L}^{-1} \quad$ Addition time $=420 \mathrm{~s}$ $\mathrm{T}_{\text {init }}=67.9^{\circ} \mathrm{C}$ 
Table 5

Estimated and statistical data at $T_{\text {ave }}=340 \mathrm{~K}$

\begin{tabular}{|c|c|c|c|}
\hline & & Value & Reference \\
\hline$k_{\text {perh }}[1 / \mathrm{mol} / \mathrm{s}]$ & & $1.42 \times 10^{-4}$ & [1] \\
\hline$E_{\text {a,perh }}[\mathrm{J} / \mathrm{mol}]$ & & 20,000 & [1] \\
\hline$k_{\text {decomp }}[\mathrm{s}]$ & & $1.28 \times 10^{-3}$ & [1] \\
\hline$E_{\mathrm{a}, \mathrm{decomp}}[\mathrm{J} / \mathrm{mol}]$ & & 95,100 & [1] \\
\hline$\Delta H_{\text {Rperh }}[\mathrm{J} / \mathrm{mol}]$ & & -4840 & [1] \\
\hline$\Delta H_{\text {Rdecomp }}[\mathrm{J} / \mathrm{mol}]$ & & $-217,000$ & [1] \\
\hline$\beta[\mathrm{J} / \mathrm{s} / \mathrm{atm}]$ & & 3.36 & [1] \\
\hline$k_{\text {R.o. }}[1 / \mathrm{mol} / \mathrm{s}]$ & & $0.90 \times 10^{-5}$ & In this work \\
\hline$E_{\mathrm{a}, \text { R.O. }}[\mathrm{J} / \mathrm{mol}]$ & & 34,000 & In this work \\
\hline \multirow[t]{2}{*}{$\Delta H_{\text {RR.o. }}[\mathrm{J} / \mathrm{mol}]$} & & $-50,000$ & In this work \\
\hline & Estimated & Standard error & Standard error \% \\
\hline$k_{\mathrm{Ep}}[1 / \mathrm{mol} / \mathrm{s}]$ & 0.014 & 0.002 & 12.7 \\
\hline$E_{\mathrm{a}, \mathrm{Ep}}[\mathrm{J} / \mathrm{mol}]$ & 72,700 & 7600 & 10.5 \\
\hline$\Delta H_{\mathrm{REp}}[\mathrm{J} / \mathrm{mol}]$ & $-116,000$ & 931 & 0.8 \\
\hline
\end{tabular}

The concentrations of FA, PFA and $\mathrm{H}_{2} \mathrm{O}_{2}$ from the aqueous phase and concentration of epoxidized oleic acid EOA from the organic phase were included in the objective function with equal weights.

The temperature dependences of the rate constants were described by the modified Arrhenius equation (Eq. (33)).

The coefficients of determination of the model were defined as follows:

$R^{2}=1-\frac{\sum\left(y_{i}-\hat{y}_{i}\right)^{2}}{\sum\left(y_{i}-\bar{y}_{i}\right)^{2}}$

where $\bar{y}$ is the mean value of the observable. The coefficient of determination of this model exceeds $99.90 \%$, showing a very good correspondence between the experimental and calculated values. Table 5 gives the estimated and statistical data for the parameters. The peroxyformic acid kinetic and thermodynamic parameters for peroxyformic acid were not estimated, because they have already been estimated from a previous article [9]. The ring-opening kinetic parameters were estimated from the previous model (Table 4 and Fig. 9).

The correlation matrix is shown in Table 6 .

Table 6 reveals that the correlations between the estimated parameters are very small, which confirms the reliability of the model. Fig. 11 shows that the model fits the experimental data. The contour plot (Fig. 12) shows that there is a clearly visible minimum

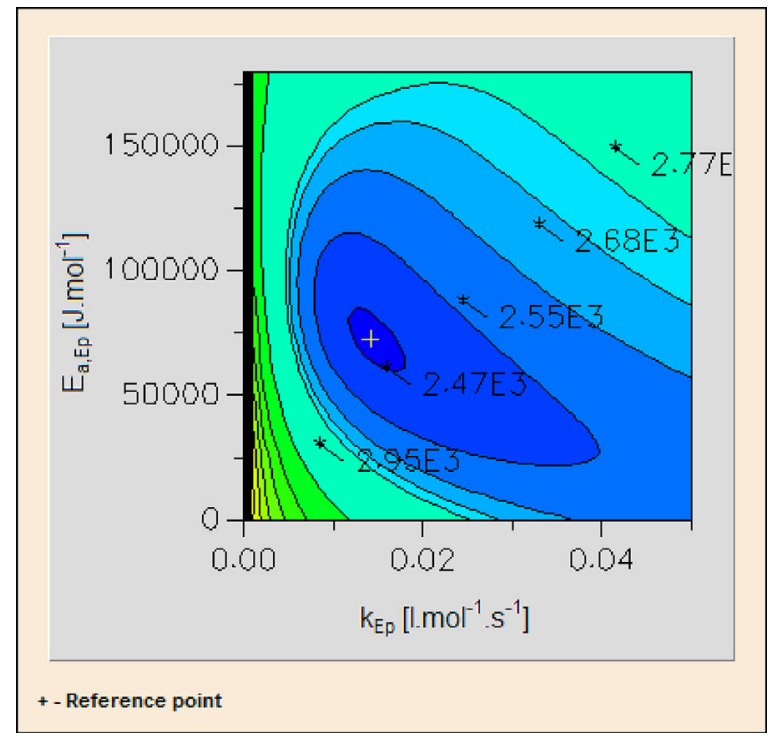

Fig. 12. Contour plot of kinetic parameters.
Table 6

Correlation matrix of parameters.

\begin{tabular}{llll}
\hline$k_{\text {Ep }}$ & 1 & & \\
$E_{\text {a,Ep }}$ & -0.205 & 1 & \\
$\Delta H_{\text {REp }}$ & -0.200 & 0.174 & 1 \\
\hline
\end{tabular}

for the activation energy and the rate constant for the epoxidation reaction. Santacesaria et al. [7] found that the heat of reaction of epoxidation was higher than the one for the ring opening. However, it was not the same chemical system and the evaporation was not taken into account.

\section{Conclusions}

The goal of this work was to develop a kinetic model for an exothermic liquid-liquid reaction system performed in a semibatch reactor under isoperibolic mode. The epoxydation of oleic acid by peroxyformic acid formed in situ was used as an example. The model is valid for 34-46 wt.\% of an organic, initial hydrogen peroxide concentration of $6.5-8.8 \mathrm{~mol} / \mathrm{L}$, formic acid molar flow rate of $0.02-0.54 \mathrm{~mol} / \mathrm{s}$, temperature range of $50-70{ }^{\circ} \mathrm{C}$. It was assumed that the solubility of the organic-phase species (oleic acid, epoxidized oleic acid) in the aqueous-phase and aqueous-phase species (water, hydrogen peroxide, formic acid) in the organic phase were practically negligible. The influence of evaporation and condensation was taken into account in the heat balance. Due to a fast mass transfer and by adding the mass balance equations of organic and aqueous phases, it was possible to avoid the use of mass transfer coefficients in the model. The reaction enthalpy for oleic acid epoxidation was estimated to be $-116 \mathrm{~kJ} / \mathrm{mol}$ and for the epoxidized oleic acid ring-opening to be $-50 \mathrm{~kJ} / \mathrm{mol}$. The activation energy for the epoxidation was estimated to be $99 \mathrm{~kJ} / \mathrm{mol}$ and for the ring-opening to $34 \mathrm{~kJ} / \mathrm{mol}$.

\section{Acknowledgments}

The financial support from Academy of Finland is gratefully acknowledged. The authors express their gratitude to Bruno Daronat, Christine Devouge-Boyer and Dr. Alain Ledoux for their technical assistance, M.Sc. Paulo Graziane and M.Sc. Frederico Safatle for the experimental work.

\section{References}

[1] Scott F. One slick trick. Environ Health Persp 2003;111(12):A654-7.

[2] Lea C. Energy savings through use of advanced biodegradable lubricants. Ind Lubric Tribol 2007;59(3):132-6.

[3] Prileschajew N. Oxydation ungesättigter Verbindungen mittels organischer Superoxyde. Ber Dtsch Chem Ges 1909;42(4):4811-5.

[4] Warwel S, Rüsch gen, Klaas M. Chemo-enzymatic epoxidation of unsaturated carboxylic acids. J Mol Catal B: Enzym 1995;1(1):29-35.

[5] Arends IWCE, Sheldon RA. Recent developments in selective catalytic epoxidations with $\mathrm{H}_{2} \mathrm{O}_{2}$. Topics Catal 2002;19(1):133-41.

[6] Bartok M, Lang KL, Patai S. The chemistry of ethers, crown ethers, hydroxyl groups and their sulfur analogues: oxiranes. New York: John Wiley \& Sons; 1980.

[7] Santacesaria E, Tesser R, Di Serio M, Turco R, Russo V, Verde D. A biphasic model describing soybean oil epoxidation with $\mathrm{H}_{2} \mathrm{O}_{2}$ in a fed-batch reactor. Chem Eng J 2011:173(1):198-209.

[8] Santacesaria E, Renken A, Russo V, Turco R, Tesser R, Di Serio M. Biphasic model describing soybean oil epoxidation with $\mathrm{H}_{2} \mathrm{O}_{2}$ in continuous reactors. Ind Eng Chem Res 2012;51(26):8760-7.

[9] Leveneur S, Thönes M, Hébert J-P, Taouk B, Salmi T. From kinetic study to thermal safety assessment: application to peroxyformic acid synthesis. Ind Eng Chem Res 2012;51(43):13999-4007.

[10] Greenspan FP, MacKellar DG. Analysis of aliphatic per acids. Anal Chem 1948;20(11):1061-2.

[11] Maerker G. Determination of oxirane content of derivatives of fats. J Am Oil Chem Soc 1965;42(4):329-32.

[12] Campanella A, Baltanás MA. Degradation of the oxirane ring of epoxidized vegetable oils with solvated acetic acid using cation-exchange resins. Eur J Lipid Sci Technol 2004;106(8):524-30. 
[13] Campanella A, Baltanás MA, Capel-Sánchez MC, Campos-Martín JM, Fierro JLG. Soybean oil epoxidation with hydrogen peroxide using an amorphous $\mathrm{Ti} / \mathrm{SiO}_{2}$ catalyst. Green Chem 2004;6(7):330-4.

[14] Campanella A, Baltanás MA. Degradation of the oxirane ring of epoxidized vegetable oils in liquid-liquid systems. I. Hydrolysis and attack by $\mathrm{H}_{2} \mathrm{O}_{2}$. Latin Am Appl Res 2005;35(3):205-10.

[15] Campanella A, Baltanás MA. Degradation of the oxirane ring of epoxidized vegetable oils with hydrogen peroxide using an ion exchange resin. Catal Today 2005;107:208-14.

[16] Campanella A, Baltanás MA. Degradation of the oxirane ring of epoxidized vegetable oils in liquid-liquid systems. II. Reactivity with solvated acetic and peracetic acids. Latin Am Appl Res 2005;35(3):211-6.

[17] Campanella A, Baltanás MA. Degradation of the oxirane ring of epoxidized vegetable oils in liquid-liquid heterogeneous reaction systems. Chem Eng J 2006;118(3):141-52.

[18] Campanella A, Baltanás MA. Degradation of the oxirane ring of epoxidized vegetable oils in a liquid-liquid-solid heterogeneous reaction system. Chem Eng Process 2007;46(3):210-21.
[19] Campanella A, Fontanini C, Baltanás MA. High yield epoxidation of fatty acid methyl esters with performic acid generated in situ. Chem Eng J 2008;144(3):466-75.

[20] Campanella A, Mandagarán BA, Campanella EA. Partitioning of carboxylic acid between oil and water phases. Experimental, correlation, and prediction. J Am Oil Chem Soc 2009;86(6):513-9.

[21] Campanella A, Rustoy E, Baldessari A, Baltanás MA. Lubricants from chemically modified vegetable oils. Bioresour Technol 2010;101(1):245-54.

[22] Ubrich O, Srinivasan B, Lerena P, Bonvin D, Stoessel F. The use of calorimetry for on-line optimisation of isothermal semi-batch reactors. Chem Eng Sci 2001;56:5147-56.

[23] Leveneur S, de Araujo Filho CA, Estel L, Salmi T. Modeling of a liquid-liquidsolid heterogeneous reaction system: model system and peroxyvaleric acid. Ind Eng Chem Res 2012;51:189-201.

[24] Haario H. MODEST-user's guide. Helsinki: Profmath Oy; 2001. 